\title{
ENTEROCUTANEOUS FISTULA AS A RARE COMPLICATION OF INGUINAL HERNIORRHAPHY: A CASE REPORT
}

Sreenidhi G.M , Nikshita N.

1. Associate Professor, Department of General Surgery, Kempegowda Institute of Medical Sciences Hospital \& Research Center, Bangalore.

2. Post-Graduate, Department of General Surgery, Kempegowda Institute of Medical Sciences Hospital \& Research Center, Bangalore.

\section{CORRESPONDING AUTHOR:}

Dr.Sreenidhi G. M,

KIMS Hospital \& Research Center,

K.R.Road, V.V Puram,

Bangalore-560004.

E-mail: nidhikavitha@yahoo.com,niki_hkr@hotmail.com

ABSTRACT: Enterocutaneous fistula is an unusual rare complication following inguinal herniorrhaphy. This case report is of a 39 year old male patient presenting with intermittent serous and feculent discharge from inguinal region for 7yrs, the clinical, imaging findings, and intra- operatively diagnosed as enterocutaneous fistula.

KEY WORDS: Enterocutaneous fistula, Inguinal Hernia, Herniorrhaphy

INTRODUCTION: Enterocutaneous fistula is a rare complication of inguinal herniorrhaphy, with no cases having been reported after review of literature. Development of enterocutaneous fistula- post herniorrhaphy is usually due to unrecognized enterotomy during strengthening of posterior wall of inguinal canal [2]. We present our experience with an enterocutaneous fistula- post herniorrhaphy due to anchoring stitch to sigmoid colon resulting in bowel injury, leading to enterocutaneous fistula.

MATERIAL AND METHODS: A 39yr old male, presented with history of Scanty feculent and serous discharge intermittently from left inguinal region for a duration of 7yrs, from 2 months post operatively after undergoing Bilateral Inguinal Herniorrhaphy at a district hospital in Tamil Nadu. He had earlier undergone superficial wound exploration twice for suspected wound infection. On clinical examination, in right inguinal region there was a scar healed by primary intention and in left inguinal region, there was serous discharge from the operative scar[Fig 1]. There was no feculent discharge on examination.

INVESTIGATIONS: Routine pre operative investigations were done, $\mathrm{Hb}-11.8 \mathrm{~g} \%$, total WBC count5100, Total protein-6.5g/dl, Serum albumin $-3.9 \mathrm{~g} / \mathrm{dl}$.

CT abdomen\& pelvis with Oral, IV, Rectal contrast and fistulogram revealed an Intra \& Extra peritoneal fistulous tract without any communication with the sigmoid colon [Fig 2].

OPERATIVE PROCEDURE: Diagnostic Laparoscopy was done, dye was injected from the cutaneous end of the fistula [Fig.3] and could be tracked down into the sigmoid colon[Fig.4] 


\section{CASE REPORT}

Procedure was converted into Laparotomy, left para median incision was placed and fistulectomy was done. Prolene sutures from sigmoid colon taken through sigmoid colon were removed [fig. 7]. The affected segment of the sigmoid colon was resected and anastomosed. Post operative period was uneventful.

DISCUSSION: The common complications of inguinal herniorrhaphy include urinary retention, superficial wound infection, serous effusion, scrotal oedema, recurrence of hernia, persistent inguinal neuralgia, ischaemic orchitis and penoscrotal haematoma, recurrence [1]. Enterocutaneous fistula is a rare clinical entity following inguinal herniorrhaphy, more commonly reported in mesh repair surgery and laparoscopic inguinal hernia repair [3]

In our case, prolene sutures were anchored to sigmoid colon, probably due to a sliding hernia. We emphasize the need for technical precision during the strengthening of posterior wall of inguinal canal to avoid such a complication.

\section{REFERENCES:}

1. Forte A, D'Urso A, Gallinaro LS, Lo Storto G, Bosco MR, Vietri F, Beltrami V:[Complications of inguinal hernia repair].G Chir 2002, 23:88-92. PubMed Abstract

2. Enterocutaneous fistula due to mesh fixation in the repair of lateral incisional hernia: a case report Sarath C Sistla*, Rajesh Reddy, Kadambari Dharanipragada and Sadasivan Jagdish

3. Burger JW, Luijendijk RW, Hop WC, Halm JA, Verdaasdonk EG, Jeekel J: Long-term Follow-up of a Randomized Controlled Trial of Suture versus Mesh Repair of Incisional Hernia.Ann Surg 2004, 240(4):578-585. 4).Leber GE, Garb JL, Alexander AI, Reed WP: Long-term complications associated with prosthetic repair of incisional hernias Arch Surg 1998, 133(4):378-82. 


\section{CASE REPORT}

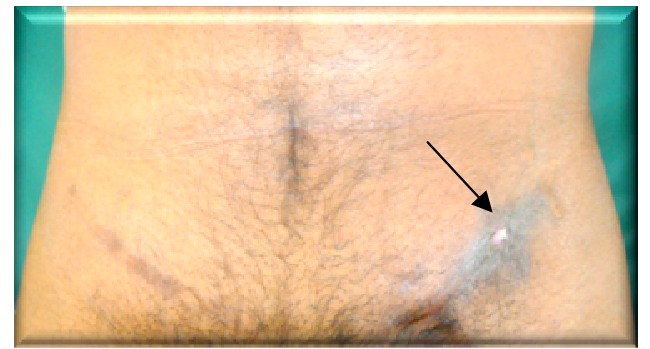

FIGURE 1-site of discharge from operative scar in left inguinal region

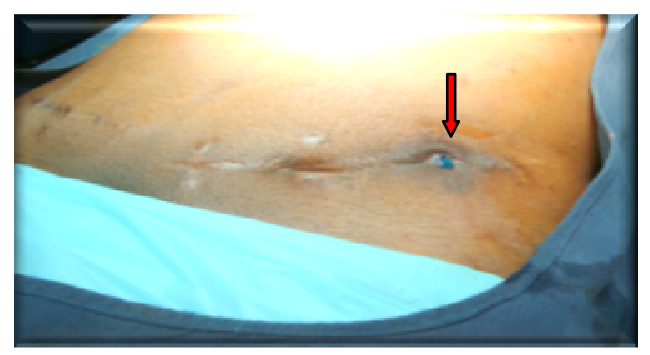

FIGURE 3-Dye injected into cutaneous end of fistula

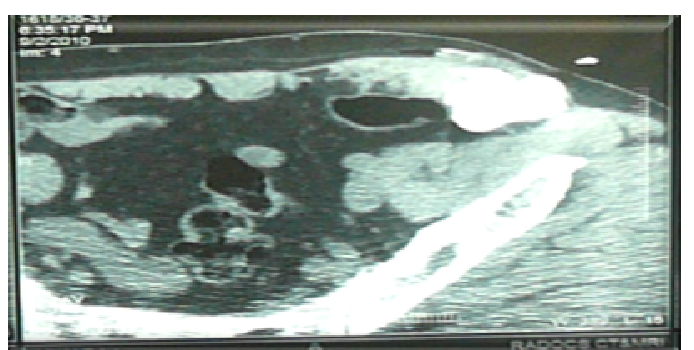

FIGURE 2- CT image, fistulogram through cutaneous end - no communication with Sigmoid colon

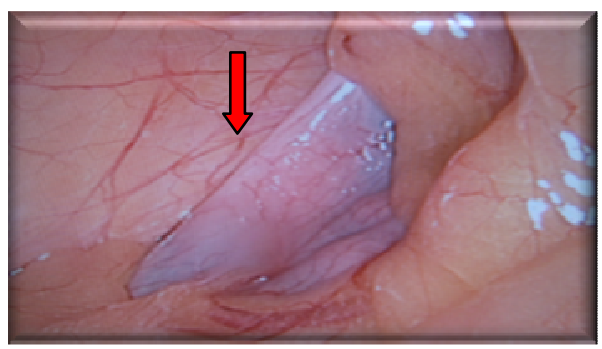

FIGURE 4-dye tracking down into sigmoid colon

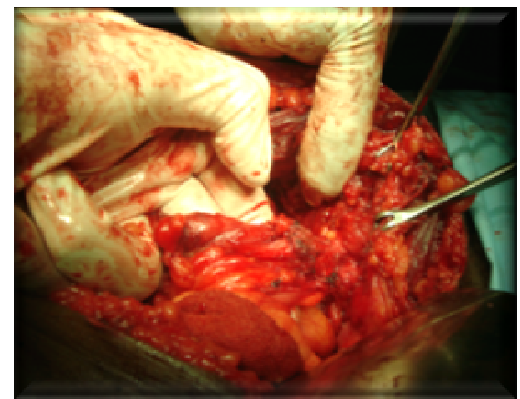

FIGURE 5-Fistula tract

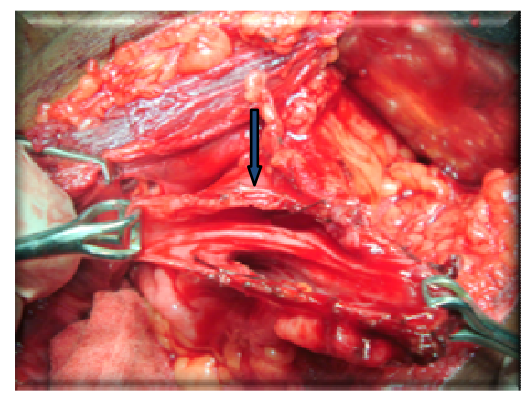

FIGURE 6-sigmoid colon with prolene sutures

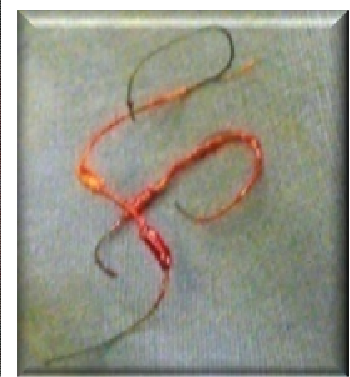

FIGURE 7-prolene suture 